\title{
Effect of Carbon Nanotube Addition on the Superconducting Properties of BSCCO Samples Textured via Laser Floating
}

\section{Zone Technique}

B. Özçelik ${ }^{1}$, I. Ergin ${ }^{1}$, T. Depçi ${ }^{2}$, H. I. Yavuz ${ }^{3}$, M. A. Madre ${ }^{4}$, A. Sotelo ${ }^{4}$

${ }^{1}$ Department of Physics, Faculty of Sciences and Letters, Çukurova University, 01330 Adana, Turkey

${ }^{2}$ Department of Engineering Science, Iskenderun Technical University, 31200 Iskenderun, Hatay, Turkey

${ }^{3}$ Department of Mechanical Engineering, Yuzuncu YIl University, 65840 Van, Turkey

${ }^{4}$ ICMA (CSIC-Universidad de Zaragoza), María de Luna, 3, 50018 Zaragoza, Spain

\begin{abstract}
In this research, the effect of carbon nanotube (CNT) addition on the structural and superconducting properties of $\mathrm{Bi}_{2} \mathrm{Sr}_{2} \mathrm{CaCu}_{2} \mathrm{O}_{\mathrm{y}}+\mathrm{x}$ wt $\%$ CNT materials with $\mathrm{x}$ $=0,0.5,1$, and 3 prepared by solid state method, followed by directional grown using the laser floating zone (LFZ) technique has been investigated. XRD measurements showed that all samples are composed of almost single $\mathrm{Bi}-2212$ phase. SEM images proved that $\mathrm{Bi}-2212$ phase is the major one, with minor amounts of $(\mathrm{Sr}, \mathrm{Ca})_{3} \mathrm{BiO}_{\mathrm{x}}$, and $\mathrm{Bi}-2201$ secondary phases. According to the magnetic results, carbon nanotubes decrease $T_{c}$ values and significantly reduce the magnetic hysteresis loops area and the magnetic critical current density.
\end{abstract}

Keywords: Bi-2212; Carbon nanotube addition; Magnetic properties; Laser floating zone technique 


\section{Introduction}

In the last decades, the interest on BSCCO for both fundamental research and applications in technology is increased day by day owing to the fact that it is one of the most promising material for potential industrial applications. The production of Bi-based high- $\mathrm{T}_{\mathrm{C}}$ superconductors is difficult compared with other $\mathrm{HT}_{\mathrm{C}}$ superconductors like YBCO. Appearing problems in these superconductors arise from the existence of three or more phases having a similar layered structure. As it is well-known that the BSCCO family are described by the $\mathrm{Bi}_{2} \mathrm{Sr}_{2} \mathrm{Ca}_{n-1} \mathrm{Cu}_{n} \mathrm{O}_{2 n+4+y}$ general formula, where $\mathrm{n}=1,2$, and 3 . The $\mathrm{n}$ value indicates the number of $\mathrm{CuO}_{2}$ layers in the crystal structure, producing the $\mathrm{Bi}$ 2201, Bi-2212, and $\mathrm{Bi}-2223$ phases with critical temperatures of approximately 20,85 , and $110 \mathrm{~K}$, respectively [1,2]. Bi-2212 phase is known to be the most stable one among the high-temperature members of this family [3,4]. Since its discovery, many studies have been performed in order to better understand its structural and physical properties, and to improve its critical temperature $\left(T_{c}\right)$ and critical current density $\left(J_{c}\right)$ [5-9]. These works have used different approaches, as doping [10-15], which leads to important changes in charge carrier concentration and also release the restriction of spin alignment due to the spin lattice interaction [16]. Besides chemical doping, grain alignment has also widely used the different production techniques to obtain high quality and homogeneous samples [17-22]. When BSCCO materials are properly textured, their transport properties are improved significantly compared with the nontextured materials [23-25]. However, two crucial factors can still restrict the transport properties in this material. One issue is the inter-grain weak links together with high anisotropy, and small coherence length due to the low extent of texture, resulting in secondary phases. The other one is the weak flux pinning resulting from intrinsic defects in their lattice structure. Therefore, to avoid some of these inconveniences, production of pinning centers has been used to enhance superconducting properties [26-30]. For many years, researchers have used different strategies in order to overcome those disadvantages and maximize their transport properties at $77 \mathrm{~K}$. One of the most successful techniques is the laser floating zone (LFZ), which has demonstrated to be an effective route to produce a good grain orientation in pure and doped $\mathrm{Bi}-2212$ superconductors [31-35]. This method produces very high thermal gradients in 
the solidification front, producing a preferential alignment of grains with their caxis perpendicular to the growth direction, maximizing the transport properties along the growth axis direction.

It has previously been shown that it is possible to embed nanotubes inside a BSCCO matrix with a subsequent enhancement in the inter-grain critical current density, due to the fact that carbon nanotubes have a shape and size similar to that of columnar defects induced in BSCCO by irradiation [36-38]. In these studies, however, a secondary detrimental effect in the superconductor has been encountered due to the reaction between carbon and oxygen. Additionally, in order to embed the carbon nanotubes in BSCCO, the wetting of carbon nanotubes was used for enhanced flux pinning [39].

In this study, we have aimed to explore the effect of carbon nanotubes in addition to the superconducting properties of BSCCO system prepared by solid state route, followed by texturing via LFZ technique, by using X-ray diffraction, scanning electron microscopy, energy dispersive X-ray spectroscopy, dcmagnetization, magnetic hysteresis, and magnetic critical current density.

\section{Experimental Procedure}

The initial $\mathrm{Bi}_{2} \mathrm{Sr}_{2} \mathrm{CaCu}_{2} \mathrm{O}_{x}$ polycrystalline materials used in this work were prepared by the classical solid state route from commercially available $\mathrm{Bi}_{2} \mathrm{O}_{3}$ (Panreac, $98+\%$ ), $\mathrm{SrCO}_{3}$ (Panreac, $98+\%$ ), $\mathrm{CaCO}_{3}$ (Panreac, 98,5 + \%), and $\mathrm{CuO}$ (Panreac, $97+\%)$. The powders were weighed in stoichiometric proportions, mixed, and ball-milled using agate balls and acetone media for 30 min at $300 \mathrm{rpm}$. The homogeneous suspension was dried using IR radiation followed by a two step thermal treatment consistently heating at 750 and $800{ }^{\circ} \mathrm{C}$ for $12 \mathrm{~h}$, with an intermediate manual milling. Then, 0.5, 1, 3, and $5 \mathrm{wt} \%$ of carbon nanotubes (CNTs) (Sigma-Aldrich, $98+\%$ ) were added to the precursor. In order to homogeneously distribute the CNTs, the mixtures were suspended in alcohol and sonicated for $10 \mathrm{~min}$, and then dried under IR radiation. The powder CNT mixtures were isostatically pressed in form of cylinders (between 2 and $3 \mathrm{~mm}$ diameter) at $200 \mathrm{MPa}$, and used as feed in a directional solidification process performed in a LFZ installation [24]. The textured bars were obtained using a continuous power Nd:YAG laser $(\lambda=1064 \mathrm{~nm})$, under air, at a growth rate of $30 \mathrm{~mm} / \mathrm{h}$ and $18 \mathrm{rpm}$ relative rotation between seed and 
feed. After the melt-grown processes, very geometrically homogeneous bars were obtained ( $\sim 2 \mathrm{~mm}$ diameter and $120 \mathrm{~mm}$ length). On the other hand, as it is well known, $\mathrm{Bi}-2212$ ceramic presents incongruent melting, producing different secondary phases as $\mathrm{Bi}-2201, \mathrm{CaCuO}_{2}$, or $(\mathrm{Sr}, \mathrm{Ca}) \mathrm{CuO}_{2}$ [22]. As a consequence, after the directional solidification process, it is necessary to perform a thermal treatment in order to form the $\mathrm{Bi}-2212$ superconducting phase [40]. This annealing process was performed under air and consisted in two steps: $60 \mathrm{~h}$ at $860^{\circ} \mathrm{C}$, followed by $12 \mathrm{~h}$ at $800^{\circ} \mathrm{C}$, and, finally, quenched in air to room temperature.

X-ray diffraction measurements were performed with a Rigaku D/max-B X-ray powder diffractometer (CuKa radiation) with $2 \theta$ ranging between 3 and 80 degrees. The uncertainty of the crystal lattice parameters calculation remained in the \pm 0.00001 range. Microstructural features were determined on polished longitudinal cross-sections of samples, in a field emission scanning electron microscope (FESEM, Zeiss Merlin) equipped with an energy dispersive spectroscopy (EDX) system. The magnetic hysteresis measurements of samples were performed at $10 \mathrm{~K}$ under $\pm 1 \mathrm{~T}$ applied field, and $\mathrm{M}(\mathrm{T})$ measurement was obtained under 50 Oe applied field in ZFC mode with a 7304 model Lake Shore VSM.

\section{Results and Discussion}

In order to detect any possible variations in the structure and the unit cell due to the CNT addition, X-ray diffraction technique was performed. The XRD patterns for pure BSCCO and BSCCO samples with different CNT concentrations are shown in Fig. 1. The XRD pattern of the 0.5 and $1 \mathrm{wt} \%$ carbon nanotube samples match with that of pure single Bi-2212 phase, while $3 \mathrm{wt} \%$ CNTsample shows several secondary phases. This difference may be caused by a possible effect of CNTs on the phase equilibria.

SEM observations performed in these samples are given in Fig. 2, for 0.5, 1 , and $3 \mathrm{wt} \%$ CNTs, respectively. In these images, CNTs can be observed between the grains of the BSCCO matrix. Their sizes are ranging between 10 and $14 \mathrm{~nm}$, and appear in the BSCCO grain boundaries, in agreement with literature [39]. 
Representative SEM micrographs of longitudinal polished sections of samples are presented in Fig. 3. As can be easily observed in the micrographs, all samples are composed by a mixture of different contrasts associated, through EDS, to different phases. Major contrast indicated by \#3 and \#4 in all samples is the gray one, corresponding to the superconducting Bi-2212 phase. Dark gray (\#2) and white (\#1) ones are the $(\mathrm{Sr}, \mathrm{Ca})_{3} \mathrm{BiO}_{\mathrm{x}}$, and $\mathrm{Bi}-2201$ secondary phases, respectively. In addition, it can be observed that CNT addition clearly reduces the size of secondary phases and grain alignment.

Figure 4 presents magnetization, $\mathrm{M}$, versus temperature, $\mathrm{T}$, for all samples obtained under 50 Oe applied magnetic field perpendicular to the fibers growth direction. The $M(T)$ measurement data were taken by cooling the sample in zero field down to $10 \mathrm{~K}$, then applying 50 Oe magnetic field, and collecting data on warming up to $100 \mathrm{~K}$. As it can be seen in the graph, the critical onset temperatures, $\mathrm{T}_{\mathrm{C}}$, corresponding to the diamagnetic transition are shifted to lower temperatures with increasing CNT content. The onset temperatures are determined as $90,84,78$, and $62 \mathrm{~K}$ for the pure, and $0.5,1$, and $3 \mathrm{wt} \% \mathrm{CNT}$ samples, respectively. These effects are mainly caused by the granular nature of samples, and influenced by the secondary phases observed in the matrix. Thus, as a result, the grain boundaries show weak connectivity and, therefore, the magnetic field easily penetrates into the sample causing a reduction in the transition temperatures.

In Figure 5, the $\mathrm{M}-\mathrm{H}$ hysteresis loops obtained at $10 \mathrm{~K}$, under ZFC mode, are given. Hysteresis loops were determined between $\pm 1 \mathrm{~T}$ applied external fields. The results demonstrate that the pure sample exhibits the largest area, decreasing when CNTcontent is increased. With these data, the intragranular $\mathrm{J}_{\mathrm{c}}$ values of all samples have been calculated via the critical Bean model [41];

$$
J_{c}=30 \Delta M / d
$$

where $J c$ is the magnetization current density in ampéres per square centimeter of a sample. $\Delta M=M_{+}-M_{\text {- }}$ is measured in electromagnetic units per cubic centimeter, and $d$ is the thickness of the sample. Fig. 5 shows the calculated critical current density values at $10 \mathrm{~K}$, up to 1 Tesla, for all samples. In the figure, it can be seen that the intragranular critical field, $J_{C}$, calculations reveal that the pure BSCCO sample shows better superconducting properties and has the biggest $J_{C}$ values $\left(\approx 22 \times 10^{4} \mathrm{~A} / \mathrm{cm}^{2}\right)$. These results indicate that $J_{C}$ values 
significantly decrease when magnetic field is raised and the amount of carbon nanotube content is increased. It may be argued that the secondary phases cause such a kind of behavior. It is well-known that in the high-Tc superconducting material, the secondary or non-superconducting impurity phases are highly effective in the flux-pinning mechanism. Because of the increasing of those impurities; the applied fields significantly penetrate into the sample and reveal a diminishing at the critical current values.

It is well-known that the flux pinning force, FP, is directly affected by the intrinsic properties of pinning centers as size, capability, stability, density etc. Therefore, let us start analyzing deeply the nature of vortex pinning mechanism. For this purpose, we have calculated the pinning forces by using $\mathrm{FP}=\mathrm{J}_{\mathrm{C}} \times \mu_{0} \mathrm{H}$ equation [42] and exhibited in Fig. 7, for all samples, at $10 \mathrm{~K}$. As can be seen from figures, in general, the calculated pinning force values monotonically increase for low applied magnetic fields, and then start sharply to decrease around magnetic field of $8 \mathrm{kOe}$, for all samples. The $\mathrm{F}_{\mathrm{Pmax}}$ values of pure sample is higher than the value of CNT ones. The maximum pinning force is around $9 \times$ $10^{8} \mathrm{Oe}^{*} \mathrm{~A} / \mathrm{cm}^{2}$ for pure sample.

In order to better understand the nature of pinning mechanism of pure sample, we analyzed the experimentally deduced data by using the Dew-Hughes model [42] in which the reduced pinning force $F_{P} / F_{P \max }$ with respect to reduced field $b$ $=\mathrm{H} / \mathrm{H}_{\max }$ is drawn as shown in Fig. 8, by fitting equation $f_{P}\left(F_{P} / F_{P \max }\right)=b^{p}(1-b)^{q}$. For high- $T_{C}$ superconductors, there are three theoretical models [43] identified as:

$f_{P}(b)=25-16 b^{-1 / 2}(1-b / 5)^{2} ;$ normal surface pinning (2)

$f_{P}(b)=9 / 4 b(1-b / 3)^{2}$; normal point pinning (3)

$f_{P}(b)=3 b^{2}(1-2 b / 3) ; \Delta k$ pinning $(4)$

As can be seen, the experimental results for pure sample are well-matched with the normal point pinning in the limited scale.

\section{Conclusions}

In summary, in this research, a comparative study of structural, physical, and magnetic properties of CNTs added BSCCO system prepared by a conventional solid state method followed by directional growth using the laser floating zone 
(LFZ) technique, has been made. X-ray diffraction results suggested that samples with nearly single Bi-2212 phase have been produced. The patterns of the 0.5 and $1 \mathrm{wt} \%$ carbon nanotube-added samples have been matched with that of the pure BSCCO, while the XRD pattern of the $3 \mathrm{wt} \%$ CNT sample shows the presence of several secondary phases. The SEM micrographs and EDX results corroborated that $\mathrm{Bi}-2212$ were major phase with minor amounts of $\mathrm{Bi}-2201$ and $(\mathrm{Sr}, \mathrm{Ca}) 3 \mathrm{BiOx}$ phases. According to M-T results, CNTs were not successfully embedded within the BSCCO grains, but rather in grain boundaries, forming weak links and decreasing the critical temperatures. In addition, the results have also implied that the high temperatures reached in the texturing process $\left(>1000^{\circ} \mathrm{C}\right.$ ) can degrade the CNT surface, reducing their effectiveness to increase electrical conductivity by intercalation in the BSCCO matrix. From $\mathrm{M}-\mathrm{H}$ measurements, it has been observed that the magnetization values and the volume of the closed hysteresis curves have been decreased with increasing CNTs content. Employing the critical Bean model, it has been found that the increase on carbon nanotube content has produced a reduction of $J_{c}$ values. The pinning mechanism by using experimental data has also theoretically investigated. The results have shown that the pinning centers in the samples exhibit a normal point pinning nature. All these results clearly point out the effect of high temperatures, under air, on the ability of CNTs to raise electrical properties. 


\section{References}

1. Michel, C., Hervieu, M., Borel, M.M., Grandin, A., Deslands, F., Provost, J., Raveav, B.: Z. Phys. B. 86, 421 (1987)

2. Maeda, H., Tanaka, Y., Fukutumi, M., Asano, T.: Jpn. J. Appl. Phys. 27, 209 (1988)

3. Majewski, P., Hettich, B., Jaeger, H., Schulze, K.: Adv.Mater. 3, 67 (1991)

4. Majewski, P.: J. Mater. Res. 15, 854 (2000)

5. Nane, O., Özçelik, B., Abukay, D.: Ceram. Int. 42, 5778 (2016)

6. Desgardin, G., Delamare, M.P., Delorme, F., Garnier, V., Giovannelli, F., Leblond-Harnois, C., Marinel, S., Monot-Laffez, I., Rouessac, V., Wang, J.: Int. J. Inorg. Mater. 2, 609 (2000)

7. Türk, N., Gündogmus, H., Akyol, M., Yakinci, Z.D., Ekicibil, A., Özçelik, B.: J. Supercond.Nov. Magn. 27, 711 (2014)

8. Jindal, A., Jangade, D.A., Kumar, N., Vaidya, J., Das, I., Bapat, R., Parmar, J., Chalke, B.A., Thamizhavel, A., Deshmukh, M.M.: Sci. Rep. 7, 3295 (2017)

9. Lennikov, V., Özkurt, B., Angurel, L.A., Sotelo, A., Özçelik, B., de la Fuente, G.F.: J. Supercond. Nov. Magn. 26, 947 (2013)

10. Ozkurt, B.: J. Alloys Compd. 579, 132 (2013)

11. Özçelik, B., Nane, O., Sotelo, A., Madre, M.A.: Ceram. Int. 42, 3418 (2016)

12. Vinu, S., Sarun, P.M., Biju, A., Shabna, R., Guruswamy, P., Syamaprasad, U.: Supercond. Sci. Technol. 21, 045001 (2008)

13. Sarun, P.M., Vinu, S., Shabna, R., Biju, A., Syamaprasad, U.: Mater. Lett.

62, 2725 (2008)

14. Nane, O., Özçelik, B., Amaveda, H., Sotelo, A., Madre, M.A.: Ceram. Int. 42, 8473 (2016)

15. Özçelik, B., Gürsul, M., Sotelo, A., Madre, M.A.: J. Mater. Sci. Mater.

Electron. 26, 441 (2015)

16. Ando, Y., Lavrov, A.N., Komiya, S., Segawa, K., Sun, X.F.: Phys. Rev. Lett. 87, 017001 (2001)

17. Naderi, G., Liu, X., Nachtrab, W., Schwartz, J.: Supercond. Sci. Technol. 26, 105010 (2013)

18. Nane, O., Özçelik, B., Sotelo, A., Madre, M.A.: J. Eur. Ceram. Soc. 37, 1007 (2017) 
19. Chen, Y.F., Li, J., Xu, X.P.,Wang, R.L., Li, S.L., Hu, F.R., Yi, C.H., Zheng, D.N.: Supercond. Sci. Technol. 21(085005), (2008)

20. Gün, E., Özkurt, B., Özçelik, B., Madre, M.A., Sotelo, A., Diez, J.C.: J.

Mater. Sci. Mater. Electron. 28, 13120 (2017)

21. Özçelik, B., Nane, O., Sotelo, A., Amaveda, H., Madre, M.A.: J. Mater. Sci. Mater. Electron. 28, 6278 (2017)

22. Vieira, J.M., Silva, R.A., Silva, R.F., Costa, F.M.: Appl. Surf. Sci. 258, 9175 (2012)

23. Özçelik, B., Özkurt, B., Yakinci, M.E., Sotelo, A., Madre, M.A.: J.

Supercond. Nov. Magn. 26, 873 (2013)

24. de la Fuente, G.F., Ruiz, M.T., Sotelo, A., Larrea, A., Navarro, R.: Mater.

Sci. Eng. A. 173, 201 (1993)

25. Costa, F.M., Carrasco, M.F., Ferreira, N., Silva, R.F., Vieira, J.M.: Physica

C. 408,915 (2004)

26. Nane, O., Özçelik, B.: J. Mater. Sci. Mater. Electron. 27, 7633 (2016)

27. Chong, I., Hiroi, Z., Izumi, M., Shimoyama, J., Nakayama, Y., Kishio, K.,

Terashima, T., Bando, Y., Takano, M.: Science. 276, 770 (1997)

28. Özçelik, B., Gürsul, M., Sotelo, A., Madre, M.A.: J. Mater. Sci. Mater.

Electron. 26, 2830 (2015)

29. Biju, A., Sarun, P.M., Aloysius, R.P., Syamaprasad, U.: J. Alloys Compd.

454, 46 (2008)

30. Albiss, B.A., Obaidat, I.M., Gharaibeh, M., Ghamlouche, H., Obeidat, S.M.:

Solid State Commun. 150, 1542 (2010)

31. Özkurt, B., Madre, M.A., Sotelo, A., Yakinci, M.E., Özçelik, B.: J.

Supercond. Nov. Magn. 25, 799 (2012)

32. Özaslan, A., Özçelik, B., Özkurt, B., Sotelo, A., Madre, M.A.: J. Supercond. Nov. Magn. 27, 53 (2014)

33. Özçelik, B., Kaya, C., Gündoğmuş, H., Sotelo, A., Madre, M.A.: J. Low

Temp. Phys. 174, 136 (2014)

34. Sotelo, A., Mora, M., Amaveda, H., Diez, J.C., Angurel, L.A., Mayoral, M.C.:

Bol. Soc. Esp. Ceram. V. 45, 228 (2006)

35. Gündoğmuş, H., Özçelik, B., Özkurt, B., Sotelo, A., Madre, M.A.: J.

Supercond. Nov. Magn. 26, 111 (2013) 
36. Fossheim, K., Tust, E.D., Ebbesen, T.W., Treacy, M.M.J., Schwartz, J.: Physica C. 248, 195 (1995)

37. Huang, S.L., Koblischka, M.R., Fossheim, K., Ebbesen, T.W., Johansen, T.H.: Physica C. 311, 172 (1999)

38. Galvan, D.H., Li, S., Yuhasz, W.M., Kim, J.H., Maple, M.B., Adem, E.:

Physica C. 403, 145 (2004)

39. Galvan, D.H., Kim, J.H., Maple, M.B., Hirata, G.A., Adem, E.: Physica C341-348, 1269 (2000)

40. Costa, F.M., Silva, R.F., Vieira, J.M.: Physica C. 323, 23 (1999)

41. Bean, C.P.: Phys. Rev. Lett. 8, 250 (1962)

42. Dew-Hughes, D.: Philos. Mag. 30, 293 (1974)

43. Sharma, D., Kumar, R., Awana, V.P.S.: Ceram. Int. 39, 1143 (2013) 


\section{Figure captions}

Figure 1. XRD patterns of all samples. Peaks corresponding to the Bi-2212 and $\mathrm{CaCuO}_{2}$ phases are indicated by Miller indices and asterisks, respectively

Figure 2. SEM images of all CNT-added samples. Arrows indicate the carbon nanotubes

Figure 3. Representative SEM micrographs of longitudinal polished sections of samples. Numbers indicate the different phases: (1) Bi-2201; (2) $(\mathrm{Sr}, \mathrm{Ca})_{3} \mathrm{BiO}$; (3)-(4) Bi-2212 phase

Figure 4. Magnetization vs. temperature, as a function of CNTs, measured under 50 Oe applied field

Figure 5. M-H curves for all samples measured at $10 \mathrm{~K}$

Figure 6. Calculated critical current densities, $J_{c}$, of all samples at $10 \mathrm{~K}$, as a function of the applied field

Figure 7. Pinning force versus applied field at $10 \mathrm{~K}$, for the different CNT-added samples

Figure 8. Reduced pinning force $F / F_{P \max }$ versus reduced applied field $\mathrm{H} / \mathrm{H}_{\max }$ for pure Bi-2212 sample 
Figure 1

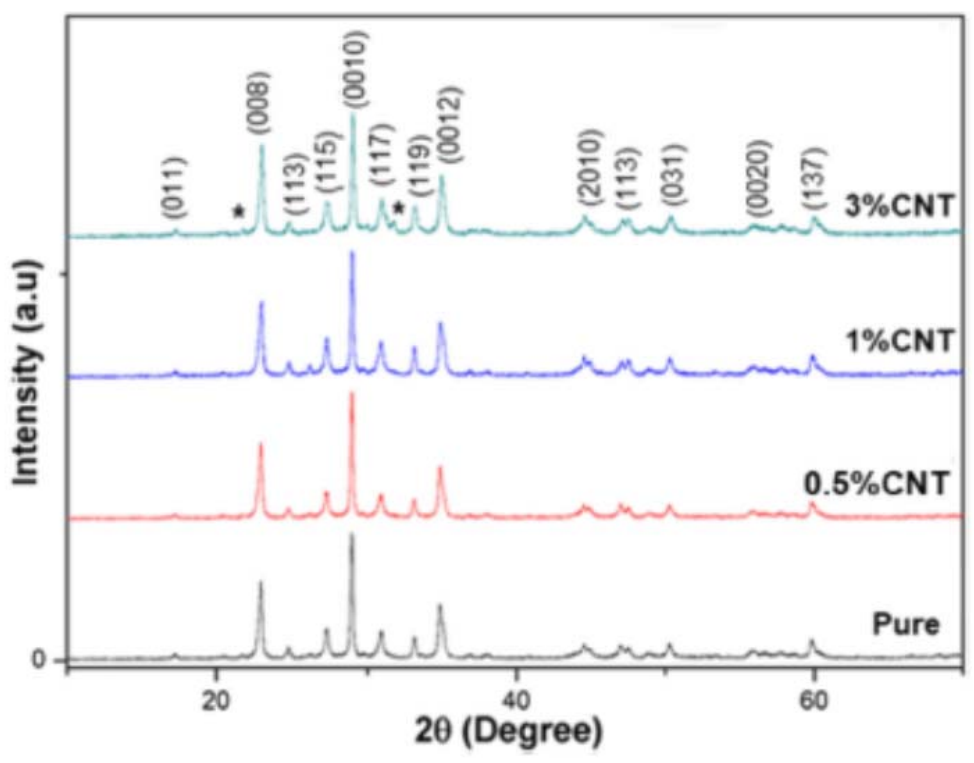


Figure 2
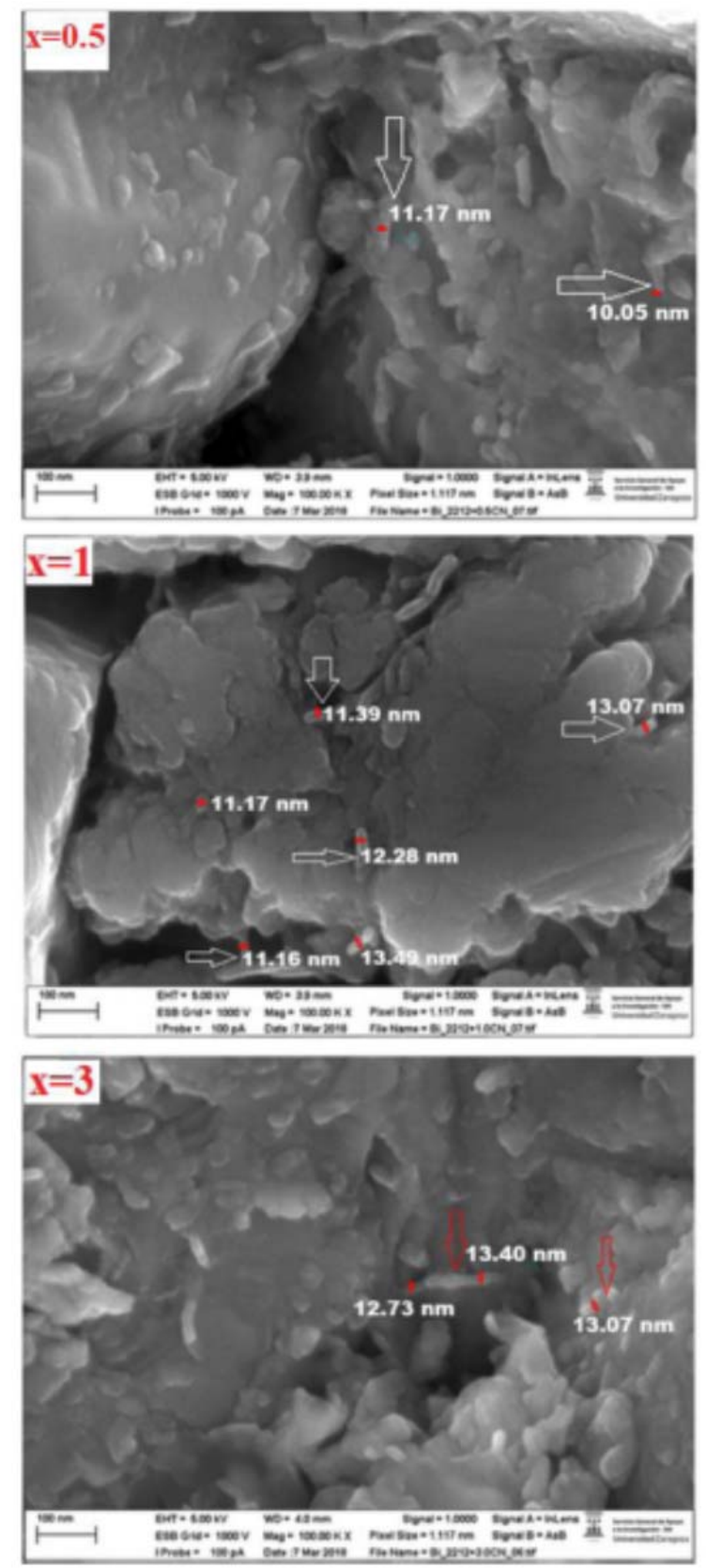
Figure 3

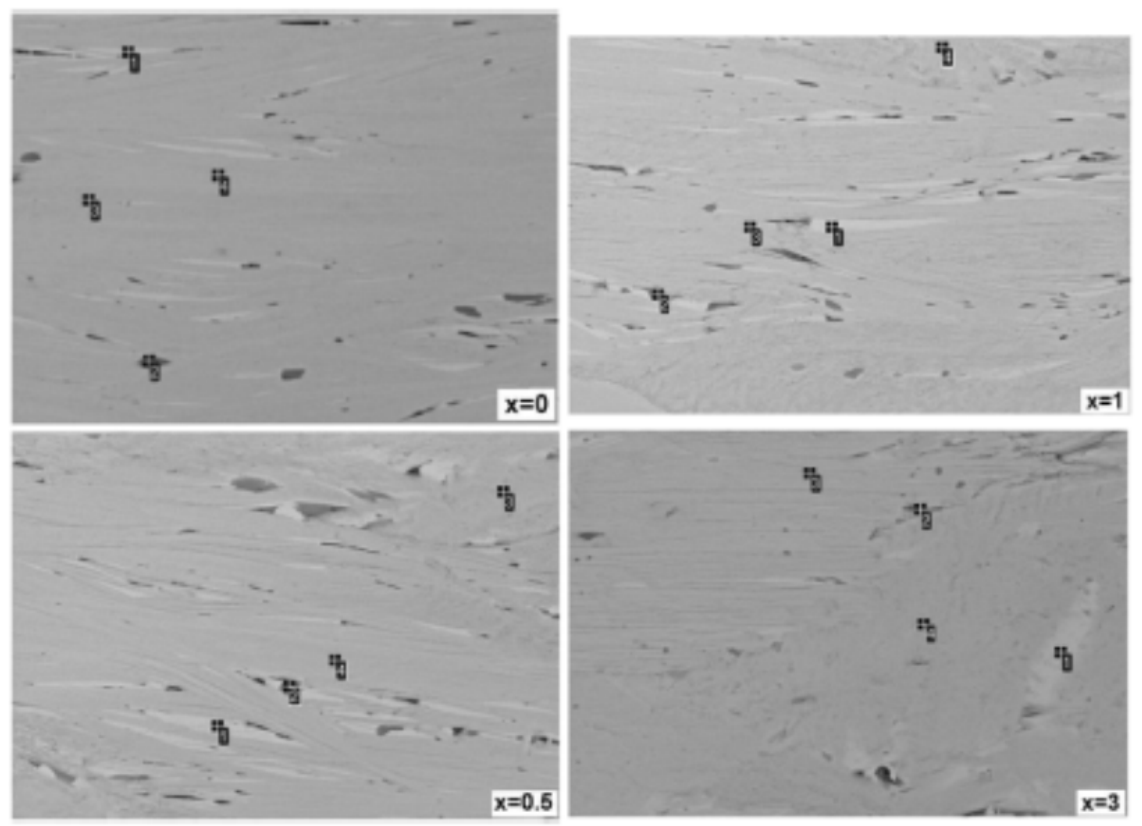


Figure 4

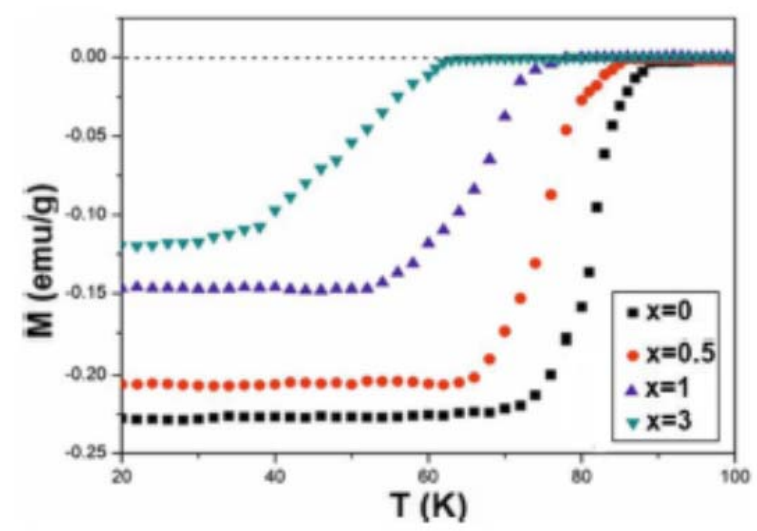


Figure 5

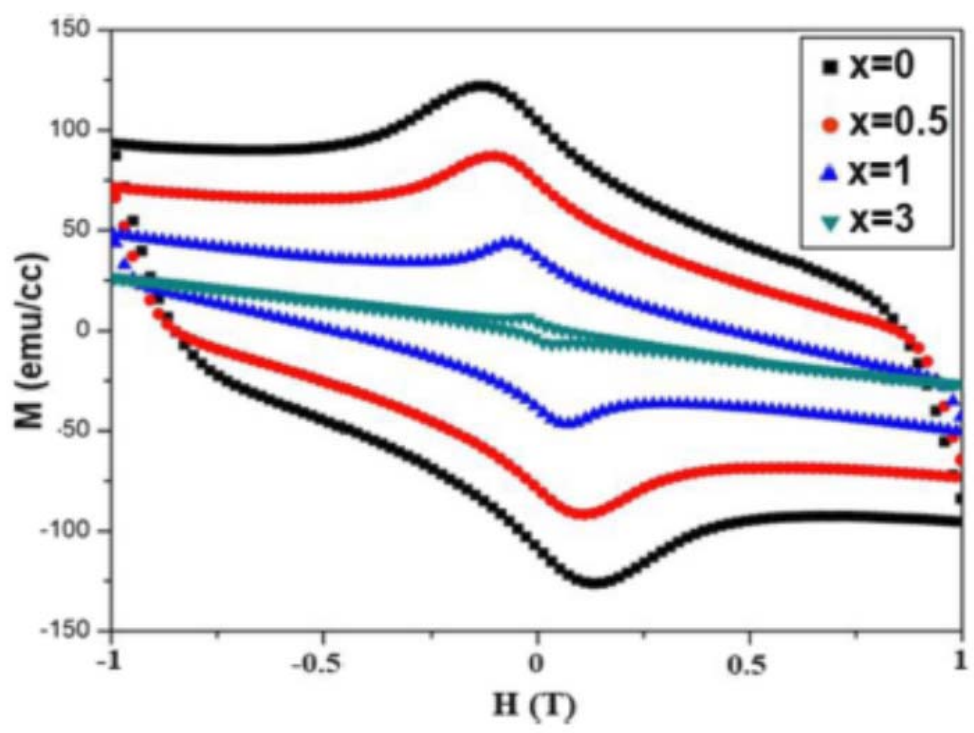


Figure 6

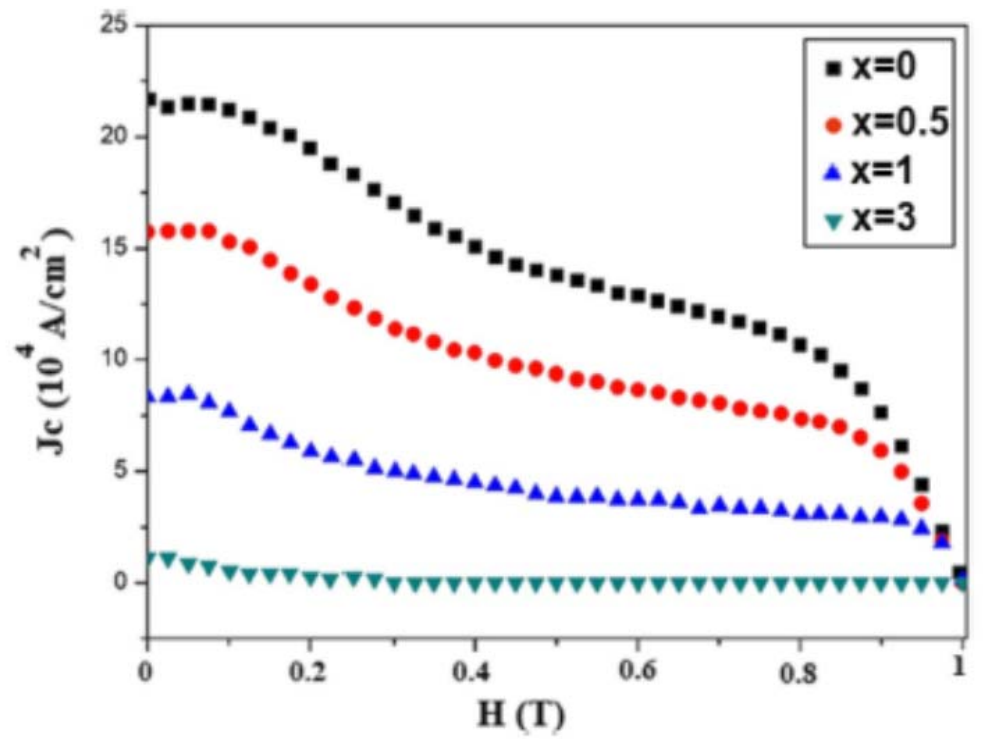


Figure 7

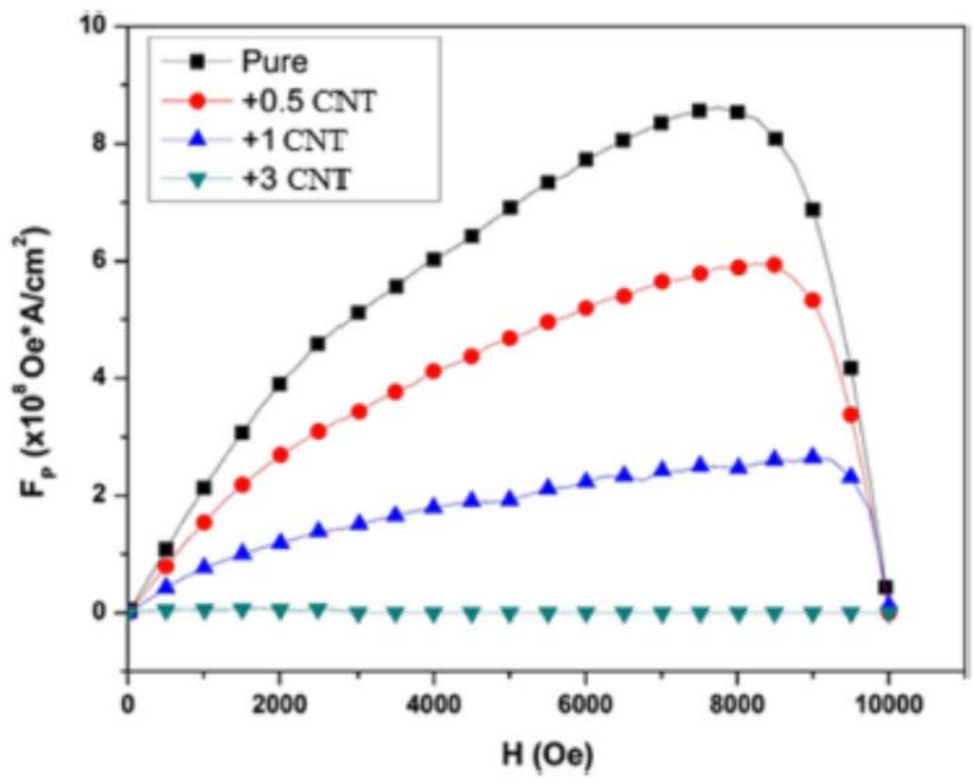


Figure 8

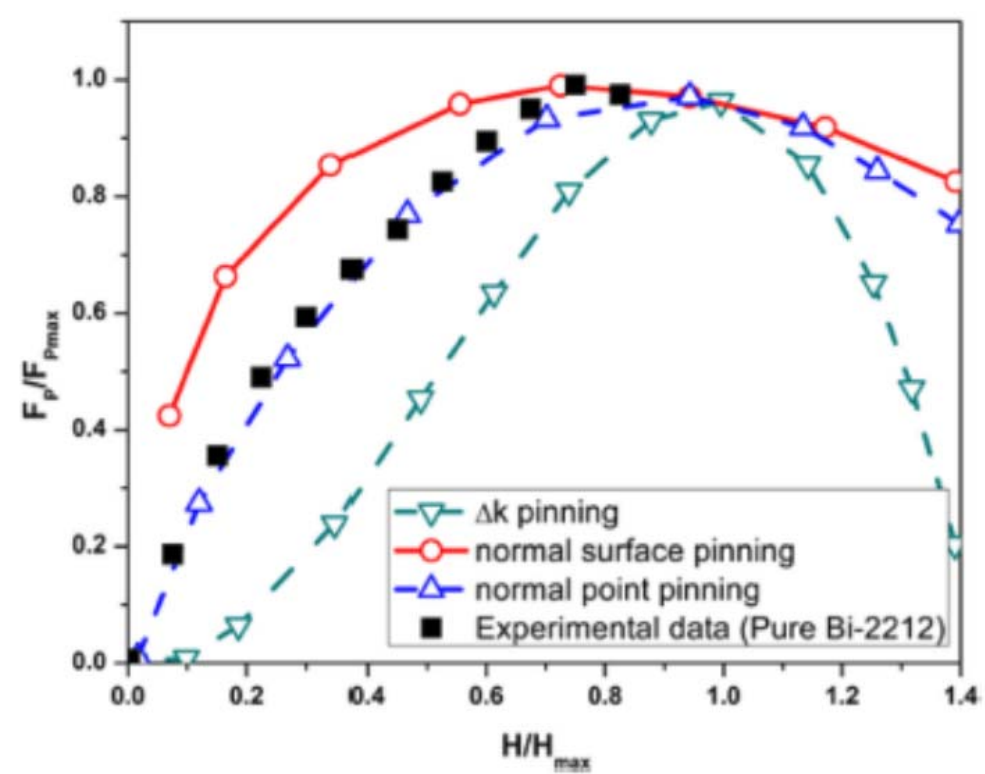

